\title{
Change Blindness and Eyewitness Testimony
}

\author{
GRAHAM DAVIES \\ SARAH HINE \\ University of Leicester
}

\begin{abstract}
The authors explored the relevance of research on change blindness to eyewitness identification and testimony under intentional and incidental memory conditions. Participants ( $N=80,40$ men and 40 women) viewed a video enactment of a burglary in which the identity of the burglar changed at the halfway point of the film. Half of participants were briefed to remember the content, and the other half were not. All were tested for the recall of the content, awareness of the change, and ability to identify either or both of the burglars. Some $61 \%$ of participants did not notice the identity change. Rates of detection were significantly higher in participants in the intentional condition, who also recalled significantly more detail from the film. Awareness of change was also significantly related to content recall scores and accuracy of identification of both burglars. The results illustrate the interrelation between the eyewitness and change blindness literatures.
\end{abstract}

Keywords: change blindness, eyewitness identification, memory

CHANGE BLINDNESS refers to the demonstrable difficulties observers face in detecting major changes in their perceptual environment. Examples include the continuity errors often overlooked in films; in one scene in Casablanca (Wallis, Curtiz, \& Epstein, 1942), Humphrey Bogart and Ingrid Bergman are seen talking across an empty table. After a reaction shot, the camera pans back to the table and a bottle and a glass have materialized in front of Bogart. There is another close-up, and when the camera pulls back again, the bottle and glass have disappeared again (see Sandys, 2006, for other examples). Change blindness has been the subject of intensive research in recent years, beginning with studies in which researchers manipulated the content of abstract scenes, but recently they have drawn on video footage or staged events (Rensink, 2002). In more dramatic

The authors thank Vicki Bruce and Mike Burton, who first brought the potential significance of change blindness for eyewitness identification to their attention.

Address correspondence to Graham Davies, School of Psychology, University of Leicester, Wellcome Building, Lancaster Road, Leicester LE1 9HN, United Kingdom; GMD@le.ac.uk(e-mail). 
demonstrations, the identity of the principal actor involved has changed during interactions with observers, but only a minority notice the change (Levin, Simons, Angelone, \& Chabris, 2002). Issues regarding the detection of identity are relevant to eyewitness testimony, yet the two literatures have so far proceeded in parallel with little acknowledgment of mutual relevance. In this article, we review the research on detecting identity change drawn from the perspectives of the change blindness and eyewitness testimony literatures and describe a study in which we attempted to build bridges between the two research traditions.

\section{Change Blindness and Identity Change}

In one of the earliest studies involving identity change (Levin \& Simons, 1997), observers viewed a video clip of an actor getting up to answer a phone call. A change in camera angle coincided with a change of identity so that the person seen answering the phone was a different actor. Despite substantial differences in physical appearance, one third of participants did not notice the change. Levin and Simons concluded that such an effect could not be attributed to inattention, given that the actions illustrated were the central event in the clip. A further study (Simons \& Levin, 1998) involved a series of staged interactions between pedestrians on a university campus and a target person who asked for directions. During the conversation, two men carrying a door came between the pedestrian and the target, enabling the target to change places with one of the men carrying the door. Even in this real-world setting, only $50 \%$ of the pedestrians reported noticing the change.

In a further series of studies, Levin et al. (2002) introduced a photo lineup to examine whether participants retained any residual visual representation of the original target. Participants unwittingly took part in either the directionfinding task or a new scenario involving a request to take a photograph of the target, in which the target changed between the request and the taking of the picture. Despite gross differences in physical appearance and clothing between the targets and their substitutes, 38\% of participants missed the change in the directions task, and 53\% missed it in the photo condition. Participants who noticed the change were significantly more likely to select the correct person from a four-person lineup than were those who did not notice (63\% vs. 26\%). In a second experiment, Levin et al. included both pre- and postchange lineups and found that although the superiority of those who noticed the change was maintained, there were no differences in accuracy of selection of the original and substitute target. The authors concluded that the poor performance of those who did not notice the change cannot be attributed to the representation of the substitute target overwriting any memory of the original.

Levin et al. (2002) were reluctant to attribute these findings to a simple lack of representation of the original target by those who did not report the change. Rather, they pointed to the results of a study by Simons, Chabris, 
Schnur, and Levin (2002) that suggest that if participants are asked sufficiently probing questions about a changed object, some participants will demonstrate tacit knowledge of the original representation. They also noted that, in a video study involving an identity change in which participants may have implicitly assumed that their memory of the content would be tested, there was no difference in accuracy of identification for the original and substitute actors on the lineup task between those who noticed and did not notice the change (Angelone, Levin, \& Simons, 2003). According to the theory of Simons et al., elaborated representations are more likely to arise from laboratory than realworld tasks; change detection requires explicit rather than implicit processing of the critical information. The observer must form a consciously accessible visual representation of the original stimulus that can be tracked over time and form a basis for later recognition (Most, Scholl, Clifford, \& Simons, 2005). However, the authors provided no direct and explicit test of their explanation for the differing findings.

\section{Face Processing and Eyewitness Testimony}

The results reported on the lack of recognition of strangers following brief interactions in the change blindness literature have a strong resonance for those familiar with recent developments in the face processing and eyewitness literature. The adage that novel faces can be rapidly encoded and subsequently effortlessly recognized (e.g., Goldstein \& Chance, 1971) has been repeatedly challenged by researchers who found the surprisingly poor identification of unfamiliar people, even under optimal conditions. Kemp, Towell, and Pike (1997) explored the effectiveness of placing the owner's photograph on a credit card as a means of preventing fraud. In a field study using experienced supermarket checkout operators, staff displayed poor accuracy in discriminating identity. Overall, checkout assistants incorrectly accepted $50 \%$ of fraudulent cards containing photographs that did not match the holder.

In a simulation of identification from closed-circuit television (CCTV) footage, Bruce et al. (1999) asked observers to simultaneously match a moving image of a target person to one of 10 still photographs, including a contemporaneous photo of the target. Even when viewpoint and expression matched, participants made errors $30 \%$ of the time. Similar effects occur irrespective of whether the target is present in or absent from the array (Davies \& Thasen, 2000). Simplifying the task by using a two alternative, forced-choice task and a high-quality color CCTV image still produced significant rates of error (Henderson, Bruce, \& Burton, 2001). However, the situation with regard to familiar people is different: people and faces that have been prefamiliarized through everyday contact are readily discriminated, even when the images are heavily degraded (Bruce, Henderson, Newman, \& Burton, 2001; Burton, Wilson, Cowan, \& Bruce, 1999). 


\section{Convergence Between the Literatures?}

The change blindness literature encompasses a wide range of effects of which blindness to identity change is but one part. Nonetheless, there appear to be considerable similarities between some of the phenomena explored by Levin et al. (2002) under a change blindness paradigm and the inaccuracies in face and person processing discovered by Bruce et al. (1999). However, there is little cross-referencing between these two research streams, and some cross-fertilization in terms of theory and practical implications would seem timely. Both emphasize a poor initial representation of the face, but the perceived locus of the problem is viewed differently. Change blindness theorists emphasize the dynamic aspects of perception and disruption in continuity of perception, with a traditional emphasis on peripheral factors, such as retinal or saccadic changes, as an explanation (Rensink, 2002). In contrast, face and person processing theorists emphasize cognitive involvement: models envisage a form of hierarchical processing in which faces are analyzed at successively deeper levels, with decisions on familiarity being made rapidly and effectively, but establishing identity requires deeper, extended processing (Bonner, Burton, \& Bruce, 2003). However, as blindness researchers have begun to explore identity change, more cognitive and attitudinal influences have been uncovered in determining the effect. Simons and Levin (1998) observed that in their door study, change was more likely to be noticed when the target was from the same age group as the pedestrian and less likely when both targets were dressed as construction workers, rather than students. Such results imply that social and cultural factors play a role in inducing change blindness.

If the common factor mediating face processing and identity change is a poor initial representation of the person involved, then variables that influence eyewitness identification should influence change blindness and vice versa. Therefore, it would seem timely to conduct studies that blend the two methodologies to explore effects of mutual interest. In this initial study, we adopted an established witness testimony paradigm in which observers watched a film of a robbery before answering a questionnaire about the content of the film and attempting to identify the perpetrator from a lineup. In keeping with the change blindness paradigm, the identity of the thief changed halfway through the film. In addition, we instructed half of participants to watch the film carefully because they would later be asked questions about it (intentional condition), whereas we instructed the other half of participants that they should watch a film about the dangers of unsecured property (incidental condition). A pilot study established that this manipulation was largely successful in influencing participants; $95 \%$ of participants anticipated a memory test in the intentional condition, compared with $35 \%$ in the incidental condition.

There were three dependant variables in this study: (a) awareness of change, (b) identification of the actors playing the burglar, and (c) scores on the content questionnaire. Levin et al. (2002) argued that watching a film under laboratory conditions would induce greater vigilance because of implicit assumptions about testing. If this 
hypothesis is correct, then participants in the intentional condition should perform better than participants in the incidental condition, both in detecting change and on knowledge of the content of the film. Further, if a common factor of increased processing was mediating both change detection and knowledge of the content of the film, then participants who noticed the change should score more highly on the content questionnaire. Last, following Levin et al., we predicted that participants who noticed change would be more likely to recognize both actors playing the burglar than would participants who did not notice the change. Although, to our knowledge, no previous researchers have investigated gender effects in change detection, we balanced gender across conditions. In the light of a meta-analysis of the eyewitness literature suggesting a small female superiority in face identification (e.g., Shapiro \& Penrod, 1986), we expected any gender difference in change detection to favor female observers.

\section{Method}

\section{Participants and Design}

A community sample of 80 people (40 men and 40 women) aged 15-65 years volunteered to participate in the study. Sixty-eight were employed, 4 were domestic carers, and 8 were students. We randomly placed participants in the intentional or incidental condition with the constraint that equal numbers of each gender should be included in the groups.

\section{Materials}

We filmed a 2-min video clip specially for this experiment depicting an opportunity theft from a student house. Halfway through the film, the actor playing the burglar changed identity. Burglar 1, the actor playing the initial part, was $1 \mathrm{~m}$ and $70 \mathrm{~cm}$ tall and slightly built with a round face. Burglar 2, the actor in the second half of the film, was considerably taller, $1 \mathrm{~m}$ and $88 \mathrm{~cm}$, and more heavily built with an oval face. Both wore dark clothing, although the style and detail of the clothing differed considerably.

The film opened with Burglar 1 trying the door handles of various houses before forcing his way inside a house. The film then showed the burglar entering the house, ransacking the front room and bedroom, and putting valuables into a rucksack before climbing the stairs. He was then seen walking down a corridor before forcing entrance into another bedroom and closing the door behind him. The camera position then changed to show the actor playing Burglar 2 coming out of the room and searching another bedroom before leaving the house with a laden rucksack. Both actors were seen continuously for approximately $1 \mathrm{~min}$ each, both in full-length and head-and-shoulders shots.

We created a content questionnaire that was prefaced by an open-ended question asking for a brief physical description of the burglar and then asked a series of 
16 questions about the film. The first question ("Did you notice anything unusual about the burglar? If so, describe.") and the last question ("Did you notice anything change about the burglar throughout the film?") probed for evidence of awareness of changed identity. The remainder were directed at details from the film (e.g., "Did the burglar leave the house through the same door he entered?").

We created a single six-person photo lineup that contained pictures of Burglar 1, Burglar 2, and four male distractors. All photographs were in color and measured 170 $\times 100 \mathrm{~cm}$. They each depicted the person concerned in a head-and-shoulders shot, dressed in casual clothing, and facing the camera. We used a single array to maximize the possibility of reintegrating memory of the two actors. To ensure the comparability of the appearance of the two targets, we gathered sets of ratings from a group of eight judges using a 7-point scale ranging from 1 (very similar) and 7 (very different) for the distinctiveness of each actor and their similarity to the other members of the lineup. The mean distinctiveness rating was 4.38 for Burglar 1 and 4.13 for Burglar 2 , an insignificant difference, $t(7)>1$. The mean similarity of Burglar 1 to the other members of the lineup was 4.10, and the corresponding figure for Burglar 2 was 3.67, also insignificant $t(7)<1$. Thus, the lineup was fair to both targets.

\section{Procedure}

Participants were tested in groups of up to 5 people by a single experimenter (one of the authors). Each group was homogeneous as to condition. When the group members were in the intentional condition, the experimenter told them, "You are about to watch a short video. Pay careful attention to the content, as there will be a memory test later." When participants were in the incidental condition, the experimenter told them, "This short video illustrates the ease and frequency of burglaries of student accommodation and the importance of keeping houses secure." Following observation of the video, all members of the group completed the questionnaire. The experimenter stressed that they should work on their own and remain silent until everyone had completed the task. The experimenter then handed each of them a board containing the lineup and requested them to select "who from this lineup you saw in the video." When the entire group had completed this task, the experimenter thanked them for their participation and asked them not to tell other people about the nature of the study. As a further precaution, we delayed debriefing about the purpose of the research until all participants had been tested.

\section{Results}

\section{Change Blindness}

The results presented as a function of condition (incidental or intentional) and change (detected or not detected) are shown in Table 1. A total of 31 of 80 
TABLE 1. Number of Participants Detecting Change as a Function of Memory Condition

\begin{tabular}{lcc}
\hline \hline & \multicolumn{2}{c}{ Change detected } \\
\cline { 2 - 3 } Condition & Yes & No \\
\hline Incidental $(n=40)$ & 5 & 35 \\
Intentional $(n=40)$ & 26 & 14 \\
Total $(N=80)$ & 31 & 49
\end{tabular}

participants reported the change (39\%). Those noticing the change were drawn disproportionately from the intentional condition, a highly significant effect, $\chi^{2}(1, N=80)=23.23, p<.001$. We conducted a hierarchical log linear analysis, adding gender to the factors of change detection and instructional condition. In addition to confirming the effect of condition on change detection, the analysis showed a significant interaction involving gender, $\chi^{2}(1, N=31)=3.88, p<.05$, such that in the intentional condition, more women than men (17 vs. 9 , respectively) detected the change, but for the incidental condition, there was no gender difference ( 2 vs. 3 , respectively).

\section{Identification of Burglar 1 and 2}

We divided performance of participants on the photo lineup into those who made no correct choices, identified one burglar, or identified both burglars. These data, presented as a function of condition (incidental or intentional) and change (detected or not detected), are shown in Table 2.

TABLE 2. Number of Participants Identifying the Actors Playing the Burglar as a Function of Memory Condition and Change Detection

\begin{tabular}{lccc}
\hline \hline & \multicolumn{3}{c}{ Identification of actors } \\
\cline { 2 - 4 } Condition and change & None & One & Both \\
\hline Incidental condition & 2 & & \\
$\quad$ Change detected & 10 & 25 & 2 \\
Change not detected & 12 & 26 & 0 \\
$\quad$ Total & 0 & 8 & 2 \\
Intentional condition & 5 & 9 & 18 \\
$\quad$ Change detected & 5 & 17 & 0 \\
$\quad$ Change not detected & & & 18 \\
Total & & & \\
\end{tabular}


A log linear analysis was precluded by an abundance of low expected cell frequencies and, consequently, we conducted separate analyses with the data partitioned in different ways. The overall distribution of choices in the intentional condition was significantly different from the incidental condition, $\chi^{2}(2, N=80)=17.57, p<.001$. Partitioning those who identified both actors from those who did not confirmed that participants in the intentional condition were significantly more likely to select both actors than were participants in the incidental condition, $\chi^{2}(1, N=80)=15.00, p<.001$. Examination of the same data categorized by whether or not change was detected confirmed that detection of change was significantly linked to differences in pattern of identification performance, $\chi^{2}(2, N=80)=42.58, p<.001$. All participants who recognized both actors detected the change, whereas none of participants who did not notice selected both burglars from the lineup. Of participants in both conditions who selected a single actor, more selected Burglar $1(n=27)$ than Burglar $2(n=16)$, but the difference was not significant on a binomial test ( $p \geq$ .13). Gender bias was consistent with that observed on change blindness: 12 of the 18 participants who correctly selected both actors were female, though this difference in favor of women was not significant on a binomial test $(p \geq .24)$.

\section{Content Questionnaire}

Performance on the content questionnaire, presented as a function of condition (incidental or intentional) and change (detected or not detected), is shown in Table 3. Detection of change was significantly correlated with scores on the content questionnaire; in general, participants who detected the change had higher questionnaire scores, $r(80)=.56, p<.001$. To examine the relation between detection of change and questionnaire scores, we conducted a $2 \times 2$ analysis of variance (ANOVA) with condition and awareness of change as main effects and gender as a covariate. Participants who detected change were more accurate than those who did not, $F(1,75)=6.91, p<.01, d=.08$. In addition, condition exerted a significant effect, with participants in the intentional condition being more accurate than par-

TABLE 3. Means and Standard Deviations of Content Questionnaire Scores as a Function of Memory Condition and Change Detection

\begin{tabular}{lccccc}
\hline \hline & \multicolumn{2}{c}{ Change detected } & & \multicolumn{2}{c}{ Change not detected } \\
\cline { 2 - 5 } Condition & $M$ & $S D$ & & $M$ & $S D$ \\
\hline Incidental & 6.20 & 0.45 & & 6.09 & 1.38 \\
Intentional & 8.69 & 1.41 & & 6.64 & 1.45 \\
Total & 8.29 & 1.60 & & 6.24 & 1.41 \\
\hline
\end{tabular}


ticipants in the incidental condition, $F(1,75)=14.56, p<.001, d=.16$. Condition and change detection were also involved in a small but significant interaction, $F(1$, $75)=5.16, p<.05, d=.03$. Examination of the interaction with a Tukey test indicated that in the intentional condition, participants who noticed the change scored significantly higher $(p<.05)$ than did participants who did not notice the change, but for participants in the incidental condition, there was no difference. Gender had no significant effects on questionnaire scores, $F(1,80)<1$.

\section{Discussion}

Despite large differences in height and build between the two men playing the burglar, only $39 \%$ of participants noticed the identity change, a figure comparable to the results of other studies in which change blindness researchers used video material (e.g., Levin \& Simons, 1997). We made predictions on the basis of Levin and colleagues' (2002) findings regarding the performance of observers on this eyewitness task. First, we predicted that the greater attention associated with a deliberate memory task would lead to a higher rate of change detection than would be found in participants who were not primed to observe carefully. This prediction was supported: $65 \%$ of participants in the intentional condition noticed the change, compared with $12.5 \%$ of participants in the incidental condition. Further, as predicted, this increase in vigilance spilled over into a significantly greater recall for film details for the participants in the intentional compared with the incidental condition on the questionnaire task. Last, we predicted that participants who noticed the change would show superior performance on the identification task compared with participants who did not notice the change. Again, there was support for this prediction: of the minority who reported the change, $56 \%$ identified both targets in the array, compared with no participants who were oblivious to the change.

In light of a small female superiority in eyewitness identification tasks, we also included gender as a factor in the study and found one significant result. Female observers were more effective at spotting the change than were men, but only in the intentional condition. This result should be treated with caution because of the low overall rates of change detection in the incidental condition, but the results are worthy of further exploration. Researchers may use stimuli modified to be of particular interest to women or men, given the impact of stereotypical gender interests on eyewitness memory (Powers, Andriks, \& Loftus, 1979). Researchers in change blindness literature have suggested that interest can exert a powerful influence on the likelihood of detecting change (e.g., Jones, Jones, Blundell, \& Bruce, 2002), further underlining the cognitive elements of the effect.

The data are equivocal in regard to the theoretical debate about whether one or two internal representations of the target arise from identity change. It is evident that participants who detected the change had a representation of Burglar 1 that 
was sufficiently complete and robust to detect the discrepancy between the two actors and, in many instances, to identify both actors from the lineup. Simons and Levin (1998) suggested that people who exhibit change blindness may lack a detailed representation of the initial actor and rely on a gist memory that is sufficiently general to accommodate the gross discrepancy in appearance of the second actor. There was some support for this theory; for example, two participants who chose the tall, more heavily built second actor as the burglar had earlier described him as "slightly built" and "stocky" — characteristics of the first actor. Such a confusion of physical attributes across targets is of practical as well as theoretical interest. It is reminiscent of the blended memories first described by Loftus (1977), whereby a compromise representation is formed to reconcile conflicting information: a red car is later referred to in a question as blue, and a minority of observers subsequently report the color of the car as green.

However, such confusions were not universal among participants who displayed change blindness and chose a single actor. If these participants were relying on a single gist memory, then one may expect that they would be more likely to recognize Burglar 1 than Burglar 2. As noted, there was a trend among those making a single choice to select Burglar 1 more often than Burglar 2, but the difference did not reach statistical significance. One could argue that one burglar was somehow more memorable than the other, and this alone would be sufficient to explain any bias in choices on the lineup. This explanation seems unlikely, given that the actors were rated as equivalent in distinctiveness, but future researchers should counterbalance the order of actors in any design to settle this point.

What of the alternative view, that separate representations of both actors are stored, but one inhibits retrieval of the other (Simons et al., 2002)? We found isolated examples in the accounts of participants that support such an inhibition model. There were responses in the questionnaire that suggested that participants who were change blind nonetheless had some inkling that a change had occurred; Rensink (2002) called this mind sight. One participant wrote, "When watching, I thought there was something different between when he was walking down the street to when he was in the house. Can't put my finger on the exact reason ... s skin tone?" Another participant wrote, "He seemed different as he left, but I couldn't work out the difference." Future researchers should use a forced-choice paradigm or use separate lineups to see if participants who report a single burglar can select the second at above-chance levels.

Our results support the theory that there are connections between the eyewitness identification and change blindness literatures. A range of variables demonstrably influence eyewitness identification (see Wells \& Olson, 2003, for a comprehensive review), and their effects could be usefully explored in a change blindness scenario. These include the familiarity of the target person (change of a familiar person should be more readily detected than change of an unfamiliar person), exposure time (change to a person seen extensively should 
be detected more readily than one seen briefly), and race (change of a person of the participant's own race should be more readily detected than another race change). There are signs of some interest in the other race effect in relation to change blindness (e.g., Humphreys, Hodsoll, \& Campbell, 2005), but little systematic research has been conducted.

In regard to practical implications, the change blindness we found in this study is another demonstration of the relatively poor accuracy eyewitnesses can show for unfamiliar people seen in brief encounters. It is possible to envisage situations in which crime witnesses display errors symptomatic of change blindness. For example, witnesses may confuse an offender seen entering a building with an innocent person seen leaving it later. Alternatively, witnesses could be convinced they had seen one offender at a crime scene when they had actually seen two different offenders successively, an example of unconscious transference (Davis, Vanous, \& Cucciare, 2000).

Our results illustrate the considerable interrelation between the eyewitness and change blindness literatures but highlight the lack of interchange between researchers in the two domains. Eyewitness researchers should take note of the relevance of change blindness research and theory to cases of mistaken identification, and change blindness researchers could use the finding of eyewitness researchers that cognition and simple vigilance both play a role in inducing change blindness (cf. Pearson \& Schaefer, 2005).

\section{AUTHOR NOTES}

Graham Davies is a professor emeritus of psychology at the University of Leicester, United Kingdom. His research interests include eyewitness testimony and identification in children and adults. Sarah Hine is a former student of the University of Leicester who currently works in the IT health care industry in London.

\section{REFERENCES}

Angelone, B. L., Levin, D. T., \& Simons, D. J. (2003). The relationship between change detection and recognition of centrally attended objects in motion pictures. Perception, 32, 947-962.

Bonner, L., Burton, A. M., \& Bruce, V. (2003). Getting to know you: How we learn new faces. Visual Cognition, 10, 527-536.

Bruce, V., Henderson, Z., Greenwood, K., Hancock, P., Burton, A. M., \& Miller, P. (1999). Verification of face identities from images captured on video. Journal of Experimental Psychology: Applied, 5, 339-360.

Bruce, V., Henderson, Z., Newman, C., \& Burton, A. M. (2001). Matching identities of familiar and unfamiliar faces caught on CCTV images. Journal of Experimental Psychology: Applied, 7, 207-218.

Burton, A. M., Wilson, S., Cowan, M., \& Bruce, V. (1999). Face recognition in poor quality video: Evidence from security surveillance. Psychological Science, 10, 243-248.

Davies, G. M., \& Thasen, S. (2000). Closed-circuit television: How effective an identification aid? British Journal of Psychology, 91, 411-426.

Davis, D., Vanous, S., \& Cucciare, M. (2000). "Unconscious transference” as an instance 
of change blindness. Retrieved March 9, 2006, from http://www.sierratrialandopinion. com/papers

Goldstein, A. G., \& Chance, J. (1971). Visual recognition memory for complex configurations. Perception and Psychophysics, 9, 237-241.

Henderson, Z., Bruce, V., \& Burton, A. M. (2001). Matching the faces of robbers captured on video. Applied Cognitive Psychology, 15, 445-464.

Humphreys, G. W., Hodsoll, J., \& Campbell, C. (2005). Attending but not seeing: The "other race" effect in face and person perception studied through change blindness. Visual Cognition, 12, 249-262.

Jones, B. C., Jones, B. T., Blundell, L., \& Bruce, G. (2002). Social users of alcohol and cannabis who detect substance-related changes in a change blindness paradigm report higher levels of use than those detecting substance-neutral changes. Psychopharmacology, 165, 93-96.

Kemp, R., Towell, N., \& Pike, G. (1997). When seeing should not be believing: Photographs, credit cards and fraud. Applied Cognitive Psychology, 11, 211-222.

Levin, D. T., \& Simons, D. J. (1997). Failure to detect changes to attended objects in motion pictures. Psychonomic Bulletin and Review, 4, 501-506.

Levin, D. T., Simons, D. J., Angelone, B., \& Chabris, C. F. (2002). Memory for centrally attended changing objects in an incidental real-world change detection paradigm. British Journal of Psychology, 93, 289-302.

Loftus, E. (1977). Shifting human color memory. Memory and Cognition, 5, 696-699.

Most, S. B., Scholl, B. J., Clifford, E. R., \& Simons, D. J. (2005). What you see is what you set: Sustained inattentional blindness and the capture of awareness. Psychological Review, 112, 217-242.

Pearson, P., \& Schaefer, E. (2005). Toupee or not toupee? The role of instructional set, centrality, and relevance in change blindness. Visual Cognition, 12, 1528-1543.

Powers, P. A., Andriks, J. L., \& Loftus, E. F. (1979). Eyewitness accounts of females and males. Journal of Applied Psychology, 64, 339-347.

Rensink, R. A. (2002). Change detection. Annual Review of Psychology, 53, 245-277.

Sandys, J. (2006). Movie mistakes take movies further. Retrieved March 8, 2006, from http://www.moviemistakes.com/film241

Shapiro, P. N., \& Penrod, S. D. (1986). Meta-analysis of facial identification studies. Psychological Bulletin, 100, 139-156.

Simons, D. J., Chabris, C. F., Schnur, T. T., \& Levin, D. T. (2002). Evidence for preserved representations in change blindness. Consciousness and Cognition, 11, 78-97.

Simons, D. J., \& Levin, D. T. (1998). Failure to detect changes to people during a realworld interaction. Psychonomic Bulletin and Review, 5, 644-649.

Wallis, H. B. (Producer), Curtiz, M. (Director), \& Epstein, P. (Writer). (1942). Casablanca [Motion picture]. United States: Warner Bros.

Wells, G. L., \& Olson, E. A. (2003). Eyewitness testimony. Annual Review of Psychology, 54, 277-295. 
Copyright of Journal of Psychology is the property of Heldref Publications and its content may not be copied or emailed to multiple sites or posted to a listserv without the copyright holder's express written permission. However, users may print, download, or email articles for individual use. 